Volume 15 - Número 1 - jan/jul de 2020

\title{
PERSPECTIVA DIALÓGICA NO LIVRO DIDÁTICO DE LÍNGUA PORTUGUESA: UM ESTUDO DISCURSIVO
}

\author{
DIALOGICAL PERSPECTIVE IN THE PORTUGUESE LANGUAGE TEACHING \\ BOOK: A DISCURSIVE STUDY
}

\author{
Wilder Kleber Fernandes de Santana ${ }^{1}$ \\ Sílvio Nunes da Silva Júnior ${ }^{2}$ \\ Pedro Farias Francelino ${ }^{3}$
}

\begin{abstract}
RESUMO: Este estudo objetiva analisar uma proposta de atividade didática de Língua Portuguesa em perspectivas dialógica e axiológica de linguagem, observando como o livro didático vem contribuindo para práticas de leitura e de escrita para além da forma linguística isolada. Assim, recorremos às contribuições de Bakhtin (2006 [1979]; 2010 [1930-34]), Medviédev (2016 [1928]) e Volóchinov (2017 [1929]) para subsidiarem a pesquisa. A abordagem dialógica tem demonstrado que há diversas possibilidades de análise das manifestações de linguagem, e que os diversos enunciados podem ser compreendidos em perspectiva discursiva. Nesse sentido, delimitamos como lócus do estudo a unidade três do livro didático Português contemporâneo - diálogo, reflexão e uso, organizado por Cereja, Vianna e Damien (2016), em que selecionamos como corpus, para análise, duas propostas de atividades a partir dos gêneros Blog e Tira. Os resultados apontaram para o fato de que as práticas de análise de linguagem sob o horizonte dos estudos dialógicos potencializam estratégias autorais na leitura e na escrita de enunciados, na medida em que instigam os sujeitos estudantes a assumirem postura reflexiva diante do texto, avaliando seus aspectos linguísticos e sócio-histórico-ideológicos. Por fim, as reflexões pontuadas neste estudo revelam a necessária adoção de uma concepção dialógica de linguagem por professores de Língua Portuguesa, para que seja possível formular práticas de ensino mais coerentes com as questões sociais que, no cotidiano, concebem uma língua em sua dimensão ampla, múltipla e concreta.
\end{abstract}

PALAVRAS-CHAVE: Língua Portuguesa. Dialogismo. Ensino.

ABSTRACT: This study aim to analyze a proposal for didactic activity in the Portuguese language in a dialogical and axiological perspective of language, observing how the textbook has contributed to reading and writing practices beyond the isolated linguistic form. Thus, we used the contributions of Bakhtin (2006 [1979]; 2010 [1930-34]), Medviédev (2016 [1928]) and Volóchinov (2017 [1929]) to support the research. The dialogical approach has shown that there are several possibilities for analyzing language manifestations, and that the different statements can be understood in a discursive perspective. In this sense, we delimited unit three of the textbook Português contemporâneo - diálogo, reflexão e uso, organized by Cereja, Vianna and Damien (2016), in which we selected as corpus, for analysis, two proposals of activities from the genres Blog and Tira. The results pointed to the fact that the analytical practices of language under the horizon of dialogic studies enhance authorial strategies in the reading and writing of utterances, insofar as they encourage student subjects to assume a reflective posture before the text, evaluating its linguistic and socio-historical-ideological. Finally, the reflections punctuated in this study reveal the necessary adoption of a dialogical conception of language by

\footnotetext{
${ }^{1}$ Doutorando e mestre em Linguística pelo Programa de Pós-graduação em Linguística da Universidade Federal da Paraíba (PROLING/UFPB). Especialista em Gestão da Educação Municipal pelo Pradime-UFPB. Membropesquisador do Grupo de Pesquisa em Linguagem, Enunciação e Interação (GPLEI/CNPQ). Bolsista Capes.

2 Doutorando e mestre em Linguística pelo Programa de Pós-graduação em Linguística e Literatura da Universidade Federal de Alagoas (PPGLL/UFAL). Licenciado em Letras/Português pela Universidade Estadual de Alagoas (UNEAL). Membro do Grupo de Estudos Discurso, Ensino e Aprendizagem de Línguas e Literaturas (GEDEALL/UFAL) e do Grupo de Estudo das Narrativas Alagoanas (GENA/UNEAL).

${ }^{3}$ Doutor em Linguística pela Universidade Federal de Pernambuco (UFPE). Mestre em Língua Portuguesa pela Universidade Federal da Paraíba (UFPB). Professor Associado do Departamento de Língua Portuguesa e Linguística da UFPB e docente do Programa de Pós-graduação em Linguística da mesma instituição. Líder do Grupo de Pesquisa em Linguagem, Enunciação e Interação (GPLEI/CNPQ).
} 
Volume 15 - Número 1 - jan/jul de 2020

Portuguese language teachers, so that it is possible to formulate teaching practices that are more coherent with the social issues that, in everyday life, conceive a broad, multiple and concrete.

KEYWORDS: Portuguese Language. Dialogism. Teaching.

\section{Considerações iniciais}

Inscrever-se na perspectiva dialógica dos estudos da linguagem é reconhecer a necessidade de responsabilização dos pesquisadores que mobilizam essa perspectiva, didática ou academicamente (BRAIT; PISTORI, 2012), para abordagem de seus objetos de investigação. No contexto dos estudos dialógicos da linguagem, diante da multiplicidade de vozes que circunda as práticas sociais dos sujeitos, inserimo-nos no campo de várias produções já existentes acerca da Língua Portuguesa (ZOZZOLI, 2014; HAMMES-RODRIGUES; ACOSTA PEREIRA, 2019; SILVA-JÚNIOR, 2019; GERALDI, 2019; SANTANA, 2019). Nesse direcionamento, corroborar a imprescindibilidade de que estudos contemporâneos de Língua Portuguesa estejam norteados pela teoria dialógica do discurso nos convoca a assumir posturas concretas diante do auditório social que nos constitui (MEDVIÉDEV, 2016 [1928]), na medida em que, conforme Santana e Silveira (2019), há necessidade de se criarem efeitos de responsabilidade ativa por aquilo que assinamos e/ou enunciamos. É nesse sentido que os professores, ao assumirem a posição de pesquisadores, são instigados a refletir não apenas sobre o objeto de estudo e as palavras enunciadas, mas pelas consciências plurais (BAKHTIN, 2006a [1979]) de todos os sujeitos envolvidos nos processos de ensino e aprendizagem.

Dentre as produtivas contribuições dos estudos dialógicos, ganha destaque a postura responsiva ativa de problematizar e se posicionar perante o método formal ${ }^{4}$, uma vez que este se centraliza nas concepções imanentes e tradicionais de ensino, especificamente na questão dos mecanismos de utilização da linguagem. O próprio termo "formal" engendra ensino e averiguações linguísticas isoladas e presos a uma noção de língua como pura coisa morta (BAKHTIN, 2006d [1979]). Sobre essa crítica que vem ganhando corporalidade em estudos científicos brasileiros, recorremos a Zozzoli (2014) e Silva Júnior (2019), para quem o ensino de Língua Portuguesa não consiste em um movimento que deva ser polarizado: nem deve estar preso a aspectos formais/gramaticais da língua, nem se centralizar em questões discursivas.

Diante de tais considerações, o objetivo de nosso trabalho consiste em analisar duas propostas de atividade didática de Língua Portuguesa numa perspectiva dialógica e axiológica de linguagem, observando como o livro didático vem contribuindo para práticas de leitura e de escrita para além da forma linguística isolada. Desse modo, esse estudo se insere em uma área de investigação que busca subsídio teórico-metodológico nos pensamentos de Bakhtin (2006b [1979]), Medviédev (2016 [1928]) e Volóchinov (2017 [1929]), assim como seus estudiosos em terreno vernáculo, como Brait (2005), Francelino (2007), Zozzoli (2014), Silva-Júnior

\footnotetext{
${ }^{4}$ Importa esclarecer, como evidenciado por Santana (2019), que o método formal não faz referência a movimento vernáculo, mas a uma propulsão de estudos da linguagem engajada por estudiosos formalistas, sobretudo na Rússia. Medviédev (2016 [1928]), em O método formal nos estudos literários, explicita que em grande parte da Europa e com mais intensidade na Rússia, na primeira metade do século XX, houve hegemonia de ensino puramente formal de literatura e de línguas, tanto em escolas de ensino fundamental e médio quanto em centros universitários. Grillo nos ajuda a compreender que alguns grupos, em terreno russo, a exemplo da Sociedade para o Estudo da Língua Poética (OPOYAZ), propunham um estudo mediante o qual houvesse a distinção entre linguagem prática e linguagem poética. Integravam esse grupo, com surgimento entre 1916 e 1917, "Viktor Chklóvski (1893-1984), Iury Tiniánov (1894-1943), Boris Eikhenbaum (1886-1959), Viktor Vinográdov (18951969), Viktor Jirmúnski (1891-1971) e o próprio Lev Iakubínski (1892-1946)” (GRILLO, Ensaio introdutório, 2017, p. 42).
} 
(2019), Santana (2019), dentre outros. Tomamos como alicerce o dialogismo e a axiologia, conceitos centrais para o entendimento da teoria dialógica da linguagem.

Nesse ínterim de discussões, estruturamos o presente artigo em três seções: a primeira, intitulada Abordagem dialógica do discurso, apresenta vozes de Bakhtin e do Círculo para fundamentar nossos dizeres sobre a pertinência dos estudos dialógicos da linguagem. A segunda seção, Axiologia e o ensino de Língua Portuguesa, traça um empreendimento teórico sobre práticas concretas de ensino de Língua Portuguesa tendo em vista o fenômeno da compreensão. A terceira seção, Trilhando caminhos concretos: análise dialógico-axiológica de enunciados, agrega a análise, em que selecionamos como corpus duas propostas de atividade do livro didático Português contemporâneo - diálogo, reflexão e uso, a partir do gêneros Blog e Tira. Esse livro foi organizado por Cereja, Vianna e Damien (2016).

\section{Abordagem dialógica do discurso}

Falar em abordagem dialógica do discurso é circunscrever e delimitar uma perspectiva teórica que articula três grandes conceitos: linguagem, sujeito e história. A Análise Dialógica do Discurso, doravante ADD, como teoria de interpretação, consiste em uma expressão que faz referência ao pensamento do filósofo russo Mikhail Bakhtin (1895-1975), em diálogo com os pressupostos sociológicos de Pável Medviédev (1891-1938) e de Valentin Volóchinov (18951936), integrantes do chamado Círculo de Bakhtin. Analisar dialogicamente um discurso é situá-lo historicamente, averiguar suas condições socioideológicas e extraverbais de produção e colocá-lo em relação com outros discursos na complexa cadeia da comunicação socioverbal.

No entanto, antes de situarmos o dialogismo historicamente no nível ético (da vida humana), cabe reconhecermos suas condições de produção, ou seja, a matriz geradora do pensamento de Bakhtin, a qual tem início em terrenos filosófico e literário. Em seu escrito filosófico inacabado intitulado Para uma filosofia do ato responsável (2010 [1920-24]), Bakhtin traz, pela primeira vez, suas reflexões sobre a linguagem, ao pontuar que "Historicamente a linguagem desenvolveu-se a serviço do pensamento participante e do ato, e somente nos tempos recentes de sua história começou a servir o pensamento abstrato" (BAKHTIN, 2010 [1920-24], p. 80). Em mesma linha de pensamento, atesta o filóso fo soviético que a expressão do ato ganha concretude "a partir do interior e a expressão do existir-evento único no qual se dá o ato exigem a inteira plenitude da palavra: isto é, tanto o seu aspecto de conteúdo-sentido (a palavra-conceito), quanto o emotivo-volitivo (a entonação da palavra), na sua unidade" (BAKHTIN, 2010 [1920-24], p. 80).

Nessa linha de pensamento, Brait (2005), em seu escrito Bakhtin e a natureza constitutivamente dialógica da linguagem, entende que a abordagem dialógica ganha respaldo "na busca da compreensão das formas de produção do sentido, de significação, e as diferentes maneiras de surpreender o funcionamento discursivo" (BRAIT, 2005, p. 87). Essa postura responsiva, ainda conforme a pesquisadora brasileira, impeliu Bakhtin na busca de uma estética e de uma ética da linguagem com elevado nível de sistematização, tendo como expoentes máximos, na literatura, Rabelais (1494-1553) e Dostoiévski (1821-1881).

O conceito que fundamenta essa reflexão, nesse entendimento, é o de relações dialógicas, que aparece de forma mais desenvolvida em Problemas da poética de Dostoiévski (2005[1963]), particularmente no capítulo 5, O discurso em Dostoiévski, em que o autor trata da noção de discurso bivocal. A bivocalidade consiste em um fenômeno discursivo no qual a palavra é duplamente orientada: tanto para o objeto do discurso quanto para um outro discurso (BAKHTIN, 2005 [1963]). É no escopo da literatura, ao incidir sobre os romances de Dostoiévski, que Bakhtin formula o conceito de relações dialógicas, interligando a vida à arte, problematizando e repensando os conceitos de linguagem e língua como promulgadas nos moldes da linguística estruturalista. Conforme Bakhtin, as relações dialógicas são 
Volume 15 - Número 1 - jan/jul de 2020

extralinguísticas (BAKHTIN, 2005 [1963]), isto é, elas se estabelecem numa dimensão que circunscreve o sistema da língua, não se esgotando nele, mas estabelecendo-se via interação discursiva (VOLÓCHINOV, 2017 [1929]). Nas palavras do autor,

As relações dialógicas são irredutíveis às relações lógicas ou concretosemânticas, que por si mesmas carecem de momento dialógico. Devem personificar-se na linguagem, tornar-se enunciados, converter-se em posições de diferentes sujeitos expressas na linguagem para que entre eles possam surgir relações dialógicas (BAKHTIN, 2005 [1963], p. 209).

Assevera Bakhtin, em seu escrito Metodologia das ciências humanas, que a compreensão se efetiva a partir do seu "desmembramento em atos particulares. Na compreensão efetiva, real e concreta, eles se fundem indissoluvelmente em um processo único de compreensão, porém, cada ato particular tem autonomia semântica (de conteúdo) ideal e pode ser destacado do ato empírico concreto" (BAKHTIN, 2006d [1979], p. 398). É nesse campo interpretativo que se alcança a "compreensão ativo-dialógica (discussão-concordância). A inserção no contexto dialógico. O elemento valorativo na compreensão e seu grau de profundidade e universalidade" (BAKHTIN, 2006d [1979], p. 398).

Quanto ao dialogismo, em definição teórica, nasce de perspectivas de confrontação de Bakhtin em relação à palavra isolada, presa a sentidos únicos e constitui a base central do pensamento do filósofo soviético, o qual afirma a palavra como viva, concreta, real. Enquanto o monologismo nega a capacidade do diálogo por conceber uma voz que se sobrepõe a outras, apagando-as, o dialogismo é primado como o princípio constitutivo da linguagem, em sua vivacidade cronotópica, e não como uma "pura coisa morta, dotada apenas de aparência" (2006d [1979], p. 393), em concordância com o pesquisador russo em Metodologia das ciências humanas. É sobretudo graças à abordagem dialógica da linguagem que, segundo Bakhtin, no manuscrito A ciência da literatura hoje (2017 [1970], p. 14), "As obras dissolvem as fronteiras de sua época, vivem nos séculos, isto é, no grande tempo, e além disso levam frequentemente uma vida mais intensa e plena do que em sua atualidade”. Afirma Bakhtin, sobre a natureza dialógica da vida humana, que

A única forma adequada de expressão verbal da autêntica vida do homem é o diálogo inconcluso. A vida é dialógica por natureza. Viver significa participar do diálogo: interrogar, ouvir, responder, concordar, etc. Nesse diálogo o homem participa inteiro e com toda a vida: com os olhos, os lábios, as mãos, a alma, o espírito, todo o corpo, os atos. Aplica-se totalmente na palavra, e essa palavra entra no tecido dialógico da vida humana, no simpósio universal (BAKHTIN, 2006e [1979], p. 348).

O dialogismo, como horizonte teórico-metodológico, não apenas pressupõe sujeitos situados socio-historicamente, mas sobretudo a linguagem em sua atualidade, com seus pontos de vista, tons axiológicos e o alcance de elementos extraverbais (VOLÓCHINOV, 2017 [1929]). Medviédev também compartilha dessa ideia ao propor que

Todos os atos individuais participantes da criação ideológica são apenas os momentos inseparáveis dessa comunicação e são seus componentes dependentes e, por isso, não podem ser estudados fora do processo social que os compreende como um todo. O sentido ideológico, abstraído do material concreto, é oposto, pela ciência burguesa, à consciência individual do criador ou do intérprete... Cada produto ideológico e todo seu "significado ideal" não estão na alma, nem no mundo interior e nem no mundo isolado das ideias e dos sentidos puros, mas no material ideológico disponível e objetivo, na 
Volume 15 - Número 1 - jan/jul de 2020

palavra, no som, no gesto, na combinação das massas, das linhas, das cores, dos corpos vivos, e assim por diante (MEDVIÉDEV, 2016a [1928], p. 49-50).

$\mathrm{Na}$ ótica do estudioso russo, caso haja cisão entre o processo cultural e o meio social em que os enunciados são construídos, não há possibilidade de haver ideologia (SANTANA, 2019). Nesse sentido, as relações dialógicas não provocam interação entre elementos inerentes ao sistema da língua, mas à sua singularidade pelo fenômeno ideológico (MEDVIÉDEV, 2016 [1928]). Esse foi um dos princípios que conduziram Bakhtin a pensar ativamente o conceito de dialogismo em contraposição à concepção monológica da enunciação. Nesse horizonte semântico-axiológico, seguiremos com uma reflexão sobre as relações entre a axiologia da linguagem e o ensino de Língua Portuguesa, visando esclarecer outras questões que embasam a análise que empreenderemos posteriormente.

\section{Axiologia e ensino de Língua Portuguesa}

A axiologia, concebida como definição teórica na esteira do pensamento de Bakhtin, é apresentada e discutida em alguns de seus textos, como em Para uma filosofia do ato responsável (2010 [1920-24]), O autor e o herói na atividade estética (2006a [1979]) e A forma espacial da personagem: o corpo exterior (2006b [1979]). Bakhtin postula que viver é tomar posição axiológica em cada vivência, ou seja, posicionar-se frente a valores, os quais têm certa estabilidade espaço-temporal. Do mesmo modo, as práticas dialogais efetivadas nas salas de aula de línguas se tornam campos ideológicos de interação verbal e não-verbal em que se incluem diferentes axiologias. "A questão axiológica é fundante no pensamento bakhtiniano, já que, pelo posicionamento valorativo, o sujeito se engaja e toma posição axiológica ou se posiciona em relação a certos valores" (ROCHA, 2018, p. 159).

No entanto, antes de nos debruçarmos sobre a conceituação e aplicabilidade da axiologia, é preciso incidir sobre suas condições de produção. É no nível estético-artístico que, inicialmente, Bakhtin elabora o conceito de axiologia, concebendo-a como um processo de valoração do autor em relação à personagem, especificamente, em $O$ autor e o herói na atividade estética (2006a [1979]). Entretanto, importa esclarecer que tal desenvolvimento teórico-conceitual ganha concretude quando Bakhtin analisa a produção romanesca de Dostoiévski, cujas personagens não são uma espécie de fantoche, nem têm suas ações totalmente vinculadas às do autor-criador, mas são independentes: cada personagem é enformada com seus pontos de vista, opiniões e posicionamentos diante do mundo.

É nessas circunstâncias que, ao destacar Dostoiévski como o produtor de um romance polifônico, Bakhtin compreende que os atos responsáveis incorporados às personagens, assim como cada significado extratemporal que cada uma ganha no existir, no existir-evento singular, possui um sentido não puramente teórico, mas possui "certo sabor axiológico" (BAKHTIN, 2010 [1920-24], p. 51). Conforme apontado por Santana (2019), as relações axiológicas constituem um elemento importante na obra, em que o autor justapõe, de modo responsável, os enunciados (e todos os outros elementos) à história e à memória ideológica sociais das personagens. Essa dimensão, axiologicamente valorativa, se faz central para a constatação da vivacidade da língua (VOLÓCHINOV, 2017 [1929]), em que autor e personagem contracenam vozes via posicionamentos valorativos.

Ao deslocarmos a axiologia para o mundo ético (da vida humana), compreendemos que as proposições de Bakhtin sobre o ser humano são constituídas por relações dialéticas e axiológicas, o que pressupõe uma relação com as esferas de atividade humana de forma que "por sua precisão e simplicidade, o diálogo é a forma clássica de comunicação discursiva" (BAKHTIN, 2006f [1979], p. 275). Atesta o filósofo russo que "viver significa ocupar uma posição axiológica em cada momento da vida, significa firmar-se axiologicamente" (BAKHTIN, 2006f [1979], p. 174) e, com isso, "efetuamos uma descrição fenomenológica da 
consciência axiológica a que tenho de mim mesmo e da que tenho do outro no acontecimento do existir" (BAKHTIN, 2006f [1979], p. 174).

Com relação às produções discursivas humanas, de acordo com Volóchinov (2019 [1926]), em A palavra na vida e a palavra na poesia: para uma poética sociológica, o enunciado é um todo significativo que comporta duas partes: a parte percebida e a parte presumida. O estudioso russo (2019 [1926]) compreende que a parte percebida de um enunciado diz respeito ao que fica evidenciado na interação discursiva (VOLÓCHINOV, 2017 [1929]), não requerendo reflexão aprofundada sobre o dizer do locutor. A parte presumida comporta o que Volóchinov denomina de extraverbal ${ }^{5}$, correspondendo a tudo o que não foi dito/apresentado explicitamente, exigindo, na interação discursiva, um grau de ativismo maior na compreensão responsiva do interlocutor (BAKHTIN, 2006a [1979]).

Diferentes questões permeiam os discursos produzidos pelos sujeitos da linguagem, uma vez que o signo, na perspectiva dialógica, é ideológico e longe de ser representado por estruturas abstratas. A manifestação da palavra como discurso destaca uma categoria da ótica axiológica do chamado Círculo de Bakhtin, a qual está voltada para o momento em que o discurso, na oralidade ou na escrita, é produzido: a entonação. A entonação deixa claro que não se pode pensar na estrutura da língua sem considerar as intenções discursivas e as condições de produção do discurso. De modo mais amplo, é impossível estudar o discurso sem que se tome como base o contexto em que o sujeito se situa.

Sobre a questão da entonação na perspectiva do ensino e da aprendizagem da Língua Portuguesa, Bezerra (2017, p. 40) depreende que "para ensinar a entoação, no sentido de atender ao que é sugerido pelo $\mathrm{MP}^{6}$, o professor precisa ter em seu universo de saberes construídos, conhecimentos da axiologia, sob a óptica bakhtiniana". Assim, o trabalho com a Língua Portuguesa vai mais além de ações pedagógicas que frisem a estrutura da língua ou práticas de produção escrita para a avaliação do produto textual. $O$ ensino da linguagem adensa num contexto problematizador que pode levar o aluno à compreensão de que o uso social da linguagem é complexo e precisa de reflexões que fundamentalmente são iniciadas na instituição de ensino. Na ótica de Bakhtin (2006c [1979], p. 117),

Ninguém pode ocupar uma posição neutra em relação a mim e ao outro; o ponto de vista abstrato-cognitivo carece de um enfoque axiológico, a diretriz axiológica necessita que ocupemos uma posição singular no acontecimento único na existência, de que nos encarnemos.

Diante disso, o domínio da axiologia traz relevantes contribuições para a discussão sobre a formação de professores de Língua Portuguesa como língua materna, bem como no que concerne ao trabalho com as línguas estrangeiras. No ensino de Língua Portuguesa, a perspectiva axiológica está imbricada em diversas atividades didáticas propostas pelo professor e, principalmente, nos materiais didáticos considerados basilares para as práticas pedagógicas,

\footnotetext{
${ }^{5}$ O extraverbal, em alguns estudos, possui outras denominações. Geraldi (1997) considera o extraverbal como uma situação histórico-social que corresponde ao espaço no qual a interação ocorre. A partir da afirmativa de Geraldi (1997), entende-se o extraverbal como uma dimensão constitutiva da linguagem que com mais ênfase aproxima o sujeito da linguagem do enunciado que produz. A parte presumida requer uma reflexão mais efetiva do locutor e do interlocutor no processo de interação que vai além do verbal, adensando, assim, no plano não-verbal da linguagem. É nessa reflexão que se encontra a questão valorativa do discurso, instituída pelo produtor e problematizada por seus interlocutores "Devido à capacidade de modificar um único enunciado, dando várias significações, a entoação é considerada criativamente produtiva nos seus aspectos sociais e discursivos" (MENEGASSI; CAVALCANTI, 2013, p. 440) Com isso, levando em conta a natureza dialógica da palavra, é possível dizer que, do ponto de vista bakhtiniano, palavra é indissociável do discurso; palavra é discurso. Mas a palavra também é história, é ideologia, é luta social, já que ela é a síntese das práticas discursivas historicamente construídas (CEREJA, 2005, p. 204).

${ }^{6}$ Manual do professor.
} 
Volume 15 - Número 1 - jan/jul de 2020

especialmente no que se refere às atividades de compreensão de textos orais e escritos. Nessa perspectiva, segundo Francelino, os sujeitos

\begin{abstract}
agem uns sobre os outros e produzem pontos de vista (posições axiológicas de sujeito). A língua é concebida como um sistema de formas em funcionamento, constituída por fatores externos como o contexto sociohistórico, a posição ideológica dos sujeitos falantes, enfim, os elementos linguísticos, que já vêm saturados pelas posições sócio-axiológicas de outrem, estão à disposição do sujeito para a produção dos mais diversos efeitos de sentido (FRANCELINO, 2007, p. 34).
\end{abstract}

Considerar a posição do outro é um ponto essencial para que o ensino não fique circunscrito a práticas estanques e desconexas de trabalho com a língua. As relações de sentido que permeiam o diálogo social configuram um pertinente espaço de construção de conhecimento, uma vez que discutir valores entre sujeitos, com diferentes formações sociais, é uma prática reflexiva que pode expandir os sentidos sobre a sala de aula.

\title{
4 Trilhando caminhos concretos: análise dialógico-axiológica de enunciados
}

Antes de adentrarmos à análise, cabe frisar que os escritos de Bakhtin e de Medviédev demarcam a importância de diferenciação entre unidade da língua e o enunciado concreto. Para os autores, as unidades da língua (palavras e orações) consistem em elementos estruturais carentes de emoção e de juízo de valor. Por outro lado, "só o enunciado tem relação imediata com a realidade e com a pessoa viva do falante (o sujeito)" (BAKHTIN, 2006d [1979], p. 328, destaque do autor). Dito de outra forma, o enunciado concreto é constituído de elementos expressivos, sentidos e ideologias (MEDVIÉDEV, 2016 [1928]).

A presente seção contém a análise dialógico-axiológica do corpus, que consiste em dois enunciados: a crônica $O$ alto preço de viver longe de casa - muito além do valor do aluguel, de autoria de Ruth Manus (2015) e a tira Sabotar a aula, produzida por Orlandeli (2016). É possível, por meio dos enunciados, compreender tanto as relações dialógicas estabelecidas com a materialidade textual-discursiva quanto o posicionamento axiológico assumido pelos autores ao elaborar as questões. Com isso, a respeito das estratégias autorais e tomadas de posição na formulação das questões, reconhecemos que "[...] cada enunciado é pleno de ecos e ressonâncias de outros enunciados com os quais está ligado pela identidade do campo de comunicação discursiva. Cada enunciado deve ser visto antes de tudo como uma resposta aos enunciados precedentes [...]" (BAKHTIN, 2006d [1979], p. 297 [destaque do autor]).

Nessa direcionalidade, após a explanação da Figura 1: Proposta de atividade do LD/EM a partir do gênero Blog, extraída da terceira seção do livro didático Português contemporâneo - diálogo, reflexão e uso (CEREJA; VIANNA; DAMIEN, 2016), são apresentadas as questões de número 2 e 5 . A escolha do livro didático analisado se dá pela repercussão que tal material possui nas salas de aula brasileiras. Na apropriação de conceitos imbricados no dialogismo, a análise não desmerece o potencial de auxílio às práticas pedagógicas de professores de língua portuguesa na educação básica. A ideia é, sobretudo, contribuir com orientações para que as atividades didáticas não se prendam ao livro, ou seja, que veicule outros conhecimentos linguístico-discursivos que podem ser construídos no trabalho com os objetos de ensino possíveis.

Nossa escolha por tais itens foi motivada por sua potencialidade argumentativa, à medida que identificamos a existência de estratégias dos autores para aguçar as habilidades reflexivas dos alunos, não permanecendo apenas em níveis morfossintáticos da Língua Portuguesa. Desse modo, passemos à Figura 1. 
Volume 15 - Número 1 - jan/jul de 2020

Figura 1: Proposta de atividade do LD/EM a partir do gênero Blog

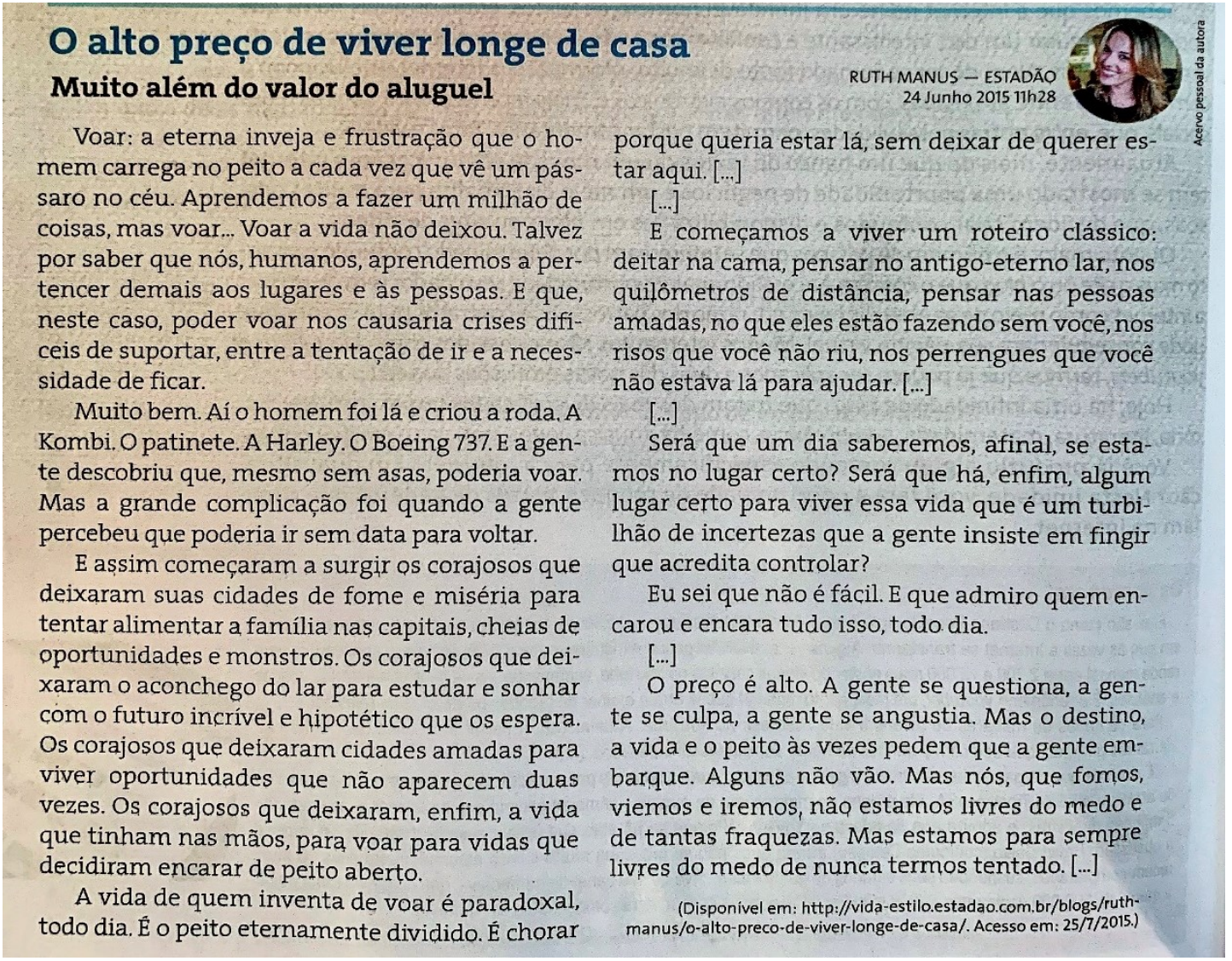

Fonte: CEREJA; VIANNA; DAMIEN. Português contemporâneo - diálogo, reflexão e uso. $1^{a}$ edição. São Paulo: Saraiva, 2016.

\section{Considere o título do texto: "o alto preço de viver longe de casa".}

a) Podemos considerar que ele é ambíguo. Justifique essa afirmação e aponte seus dois sentidos possíveis.

b) Há no texto uma expressão que explicita essa ambiguidade. Identifique-a.

\section{Ao mesmo tempo em que pode conter recursos literários, a linguagem de blogs pode se aproximar da que é usada em conversas informais. Há, no texto lido, alguns trechos que lembram uma conversa, dando a impressão de que a blogueira estivesse falando com seus leitores.}

a) Levante hipóteses: A quem a autora do blog se dirige?

b) Quais são os trechos do texto que lembram uma conversa direta com os leitores? Justifique sua resposta.

No item 2, inicialmente, os autores solicitam que o leitor considere o título do texto "o alto preço de viver longe de casa". Então, o subitem a), ao antecipar que se trata de um título ambíguo, solicita que se justifique tal ambiguidade, de forma que sejam apontados dois sentidos possíveis. Trata-se de uma questão estrategicamente elaborada que convida os leitores a realizarem leituras abrangentes, não permanecendo na estrutura da língua, mas convocando as diferentes relações dialógicas entre o título do texto e a materialidade discursiva.

Em relação ao subitem a), os autores contribuem para o desenvolvimento de uma competência leitora que leva em consideração experiências existenciais das quais o público 
leitor, alunos da faixa etária adolescente, já tem certo conhecimento: o aspecto emocional, encarnado na decisão de sair de casa em busca de realizações, mudança de vida; e, por outro lado, as consequências de ordem financeira que incidem sobre tal decisão. Em ambos os casos, os autores propõem que seus interlocutores - sem álibi, para usar um termo bakhtiniano apresentem suas visões de mundo acerca desse tema, ou seja, manifestem sua posição valorativa acerca do assunto. Já em relação ao subitem b), os autores exploram o conhecimento do aluno acerca da relação entre o projeto enunciativo (a vontade de dizer) e a materialidade sígnica que melhor materializa essa posição, isto é, instam o aluno a identificar as escolhas linguísticas que melhor se adequam e dão forma a esse dizer.

Para que os sujeitos, em sala de aula, justifiquem os sentidos possíveis para o título do texto, evidenciando sua ambiguidade, faz-se necessário que o leiam considerando, além da forma, o material e o conteúdo. Além disso, há uma espécie de subtítulo ("Muito além do valor do aluguel") que sugere para os leitores que a arquitetônica discursiva não está fazendo referência apenas aos altos preços dos alugueis que são pagos em imóveis alugados, mas, ainda, às condições a que se submetem "os corajosos que deixaram, enfim, a vida que tinham nas mãos" (MANUS, 2015). Na medida em que os interlocutores têm contato com o texto, vão estabelecendo relações dialógicas entre os enunciados, ou seja, constatando os sentidos possíveis para que a autora viesse a intitulá-lo $O$ alto preço de viver longe de casa. Em continuidade a essa perspectiva, o subitem b) solicita que seja identificada, no texto, a expressão que explicita essa ambiguidade. Nas palavras de Bakhtin (2006d [1979], p. 289), "a fala só existe, na realidade, na forma concreta dos enunciados de um indivíduo: do sujeito de um discurso-fala. $\mathrm{O}$ discurso se molda sempre à forma do enunciado que pertence a um sujeito falante e não pode existir fora dessa forma".

Ao refletirmos sobre as palavras do filósofo soviético, podemos afirmar que o enunciado mobiliza a interação discursiva (VOLÓCHINOV, 2017 [1929]) entre dois ou mais sujeitos, isto é, o enunciado concreto, por natureza, promove dialogização entre as consciências plurais: os leitores e os autores, por meio da materialidade discursiva. Essa proposta axiológica dos estudos da linguagem tem sua gênese na abordagem dialógica que dá vida à linguagem e ao sujeito, que tem direito a expressar seus pontos de vista.

Quanto ao item $\mathrm{n}^{\circ} 5$, inicialmente contextualiza os leitores sobre a linguagem de blogs, que pode conter recursos literários, bem como pode ter proximidade com interações informais. Então, explana que no texto em evidência, de autoria de Manus (2015), há determinados trechos em que aparenta existir uma conversa, como se houvesse um diálogo entre a autora do texto e seus leitores. Assim, surge, no primeiro, subitem a), um questionamento: A quem a autora do blog se dirige? Nesse momento, os autores exploram o conhecimento específico dos leitores (supostamente alunos do ensino médio) sobre o público alvo, ou seja, a quem essa palavra está sendo lançada? Para quem é direcionada a mensagem que está explicitada na construção linguístico-discursiva?

Ao recorrermos a Medviédev, em seu manuscrito Os elementos da construção artística (2016 [1928]), entendemos que a obra ou enunciado a que temos acesso ou produzido(a) por nós "se orienta para os ouvintes e os receptores, e para determinadas condições de realização e de percepção" (MEDVIÉDEV, 2016 [1928], p. 195). A partir da constatação de que os enunciados são orientados tanto para a vida quanto para a arte (VOLÓCHINOV, 2019 [1926]; BAKHTIN, 2006e [1979]), compreende-se que tais enunciados "pressupõem um ou outro auditório de receptores ou leitores, esta ou aquela reação deles, esta ou aquela relação entre eles e o leitor" (MEDVIÉDEV, 2016 [1928], p. 195). O teórico russo entende que há sempre uma dupla orientação do gênero, tanto o auditório imediato quanto um outro auditório mais amplo e a quem a palavra pode estar sendo endereçada de forma mais direta. Esse segundo auditório não precisa estar presente, mas é pressuposto quando o autor constrói o enunciado. 
Volume 15 - Número 1 - jan/jul de 2020

No caso do texto $O$ alto preço de viver longe de casa (MANUS, 2015), não é aos estudantes de ensino médio que a mensagem é direcionada, mas a todas as pessoas que sofrem por terem saído de casa e que, por isso, acabam partilhando do sofrimento que é descrito. A pergunta provoca os sujeitos a pensarem também onde, inicialmente, o texto foi produzido, por se tratar de um material que inicialmente foi publicado em um blog. Quem são os leitores de blog? Pessoas que se identificam com aquela determinada temática e sempre visitam aquela instância espaço-temporal eletrônica.

Sobre a questão do endereçamento, faz-se pertinente pontuar, conforme Bakhtin e Medviédev, que toda a enunciação dialógica é sempre orientada em direção ao outro, em direção a ouvintes ativos, ou seja, o enunciado é, sempre, orientado socialmente (BAKHTIN, 2005 [1963]; MEDVIÉDEV, 2016 [1928]), como elucida Volóchinov (2017, p. 204): "Efetivamente, o enunciado se forma entre dois indivíduos socialmente organizados [...]". Assim sendo, "não importa qual enunciado consideramos [...] concluímos que sua orientação é inteiramente social" (VOLÓCHINOV, 2017 [1929], p. 206). Por último, ao interpelar os interlocutores sobre b) que trechos do texto lembram uma conversa direta com os leitores? Justifique sua resposta, os autores conduzem os alunos a saírem do nível da especulação e adentrarem no aspecto da evidência, a procurarem na materialidade linguística os indícios concretos acerca da hipótese de leitura levantada no item 'a' da questão. Dessa forma, a atividade demanda do aluno uma postura responsável no ato de comprovar, linguisticamente, o que ele presumiu na leitura proposta na tarefa anterior. E aí é onde se manifesta a preocupação dos autores de oferecer ao estudante um espaço de compartilhamento de ideias, de valores, em que o sujeito aluno possa dispor de sua voz para expor seu ponto de vista acerca do objeto de discurso sobre o qual discorre.

Nesse sentido, a escolha das atividades que compõem esta análise foi feita mediante o potencial de reformulação de tais propostas em contextos de ensino e aprendizagem de Língua Portuguesa, dado o objetivo deste estudo de constituir reflexões coerentes com os acontecimentos que permeiam as variadas situações de trabalho com a língua materna, o que, naturalmente, envolve questões de leitura, produção de textos e gramática.

Em um processo contínuo, é possível averiguar a tomada de posicionamentos ativos por parte dos autores ao formularem questões que convocam a materialidade linguístico-discursiva, uma vez que estão levando os alunos ao diálogo entre consciências plurais (BAKHTIN, 2006a [1979]), na medida em que pode formular justificativas diferentes. O posicionamento axiológico assumido pelos autores do LD, no ato específico da formulação das questões, não é o de reprodutores de um método formal, mas de sujeitos comprometidos com uma abordagem de língua que leva em conta suas dimensões extralinguísticas, que considera como elementos primordiais para o ensino de Língua Portuguesa a forma, o material e o conteúdo (BAKHTIN, 2010 [1924]).

A seguir, a Figura 2, que veicula o segundo enunciado, a tira Sabotar a aula, produzida por Orlandeli (2016). 
Volume 15 - Número 1 - jan/jul de 2020

Figura 2: Proposta de atividade do LD/EM a partir do gênero Tira ${ }^{7}$

Leia a tira a seguir, do cartunista Orlandeli, e responda às questões de 10 a 12.
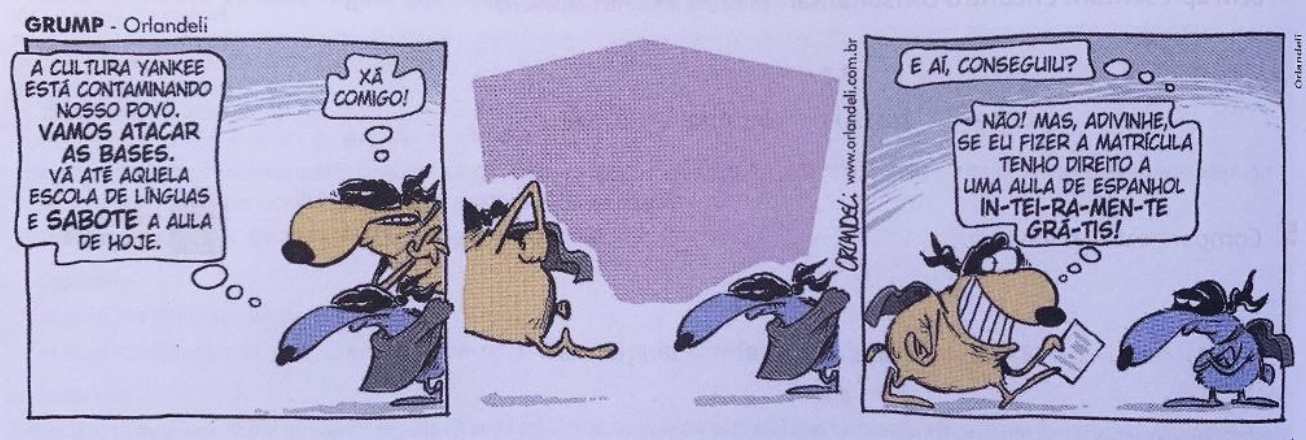

(Cedida pelo autor.)

10. Orlandeli satiriza, na tira, a influência da cultura americana no Brasil. Suas personagens, Vândalo e Fido, resolveram tornar-se heróis para combater essa infuência.

a. No primeiro quadrinho, a que aula provavelmente Vândalo se refere quando diz "a aula de hoje"?

b. De acordo com o último quadrinho, como foi o desempenho do "herói" em sua missão? Por quê?

Fonte: CEREJA; VIANNA; DAMIEN. Português contemporâneo - diálogo, reflexão e uso. $1^{\mathrm{a}}$ edição. São Paulo: Saraiva, 2016.

Essa é uma proposta de atividade do LD/EM a partir do gênero Tira, extraída da terceira seção do livro didático Português contemporâneo - diálogo, reflexão e uso (CEREJA; VIANNA; DAMIEN, 2016). A questão apresentada é a número 10, dividida em dois itens (a e b).

No enunciado da questão, os autores já apresentam aspectos relevantes que orientam o leitor na atividade de leitura a ser desenvolvida. Aqui já são apresentados o gênero discursivo (tira), bem como o projeto enunciativo do autor, que é o de satirizar a "influência da cultura americana no Brasil." (CEREJA; VIANNA; DAMIEN, 2016, p. 190). Ainda faz parte do texto da questão uma breve contextualização do enredo da tira, na medida em que os autores apresentam os personagens e a ação que desenvolvem na história. Essas informações prévias apresentadas pelos autores da proposta da atividade são relevantes porque elas constituem o contexto que emoldura o enunciado lido pelo aluno e isso contribui para que ele estabeleça relações entre o conteúdo retratado (e refratado) na materialidade verbovisual e a temática ideológica apresentada, que é a da presença forte e significativa da cultura norte-americana no Brasil.

No item "a" (No primeiro quadrinho, a que aula provavelmente Vândalo se refere quando diz "a aula de hoje”?), os autores propõem uma questão que demanda do aluno a mobilização tanto de um conhecimento linguístico (palavra "yankee") atrelado a um conhecimento presumido para o qual, talvez, nem todo aluno esteja atento no ato de leitura, que

\footnotetext{
${ }^{7} \mathrm{O}$ autor da tira é Walmir Americo Orlandeli, um cartunista, quadrinista e ilustrador, formado em Publicidade e Propaganda. Atua na área de cartum e ilustração desde 1994. É um artista premiado e já realizou trabalhos para importantes revistas, como a Mens' Health, Superinteressante, Época, e jornais como Folha de São Paulo, O Pasquim 21, A Tribuna, dentre outros.
} 
Volume 15 - Número 1 - jan/jul de 2020

é o fato da influência da cultura norte-americana no nosso país. Ou seja, para que o enunciado seja compreendido, ou, em outros termos, para que o aluno apresente uma compreensão responsiva ativa à demanda colocada pelos autores na questão, é preciso que ele saiba que o signo (linguístico e ideológico) "yankee" ("ianque', em português) refere ao universo americano propriamente dito, constituindo-se praticamente como um nome gentílico dos Estados Unidos, uma vez que "estadunidense" é um termo que também pode ser usado para os mexicanos, pois o nome oficial do México é "Estados Unidos Mexicanos". Assim, a aula a que o personagem refere é a aula de Inglês, idioma oficial dos Estados Unidos da América.

Nesse sentido, a atividade encaminha o aluno para a busca de um presumido, ou seja, aquilo que no enunciado não está verbalmente realizado, de forma explícita. Os autores abordam um plano que extrapola o meramente linguístico e conduzem o aluno a trabalhar com operações linguístico-discursivas mais elaboradas, mais complexas, pois para a atribuição de sentido ao enunciado é preciso que o leitor (aluno) compartilhe do horizonte social retratado pelo autor da tira, qual seja, a questão da identidade 'ianque'. Além disso, evidentemente, é preciso que o aluno compartilhe, ainda, da ideia já comum entre nós de que no Brasil há uma maciça influência da cultura e língua norte-americanas em nossa música, culinária, literatura etc. Desse entendimento é que depende a compreensão responsiva ativa de sátira, de crítica social ao enunciado tira em questão.

No item "b" (De acordo com o último quadrinho, como foi o desempenho do "herói" em sua missão? Por quê?), o desempenho do aluno requer uma compreensão coerente com o que foi respondido no item "a" para que o efeito de humor (com tom emotivo-volitivo de sátira) se concretize. Antes, porém, chamamos a atenção para um dado que, se percebido pelo aluno, pode agregar à compreensão da questão proposta. Trata-se do uso das aspas na palavra "herói". Nesse caso, os próprios autores é que valoram, já na proposição do texto da questão, a postura desse "herói" da narrativa, ao conferir-lhe um papel de fracasso em sua missão (para usar um termo do tipo de vocabulário empregado na tira, que é do campo bélico, da guerra, conforme lemos nas palavras "vamos atacar as bases"; "sabote"). Espera-se do aluno, como compreensão responsiva ativa, que ele se posicione de forma a atestar o fracasso do personagem e, como justificativa para isso, demonstre que este não só não conseguiu sabotar a aula de inglês, como também se interessou em aprender a língua espanhola, portanto, uma disposição para submeterse à outra cultura além da norte-americana.

A proposta do item "b" da questão evidencia a postura teórico-metodológica dos autores no sentido de oferecer uma atividade de leitura para além dos aspectos formais do enunciado, exigindo do aluno uma atitude dialógica (compreensão ativo-responsiva) diante da tira, no sentido de conduzir o aluno à reflexão sobre a temática retratada (e, insistimos, refratada!). De forma particular, a proposta permite ao leitor-aluno a percepção (i) da tomada de posição axiológica do autor em relação ao assunto, materializada em forma de humor satírico pelo desempenho de uma das personagens da narrativa diante da missão que lhe foi confiada; e (ii) nas relações dialógicas que o leitor precisa estabelecer para produzir o sentido almejado, ou seja, no conhecimento que o leitor precisa ter sobre o que é cultura "yankee", bem como a forma "apaixonada" e irrefletida como o país se sujeita à cultura estrangeira (conforme vemos na postura entusiasmada do personagem em relação à aula de Espanhol).

\section{Considerações finais}

O estudo da linguagem na perspectiva dialógica nos coloca num lugar social que propicia o desenvolvimento de diferentes reflexões, neste caso, direcionadas à ampla temática 
Volume 15 - Número 1 - jan/jul de 2020

do ensino de Língua Portuguesa e, de forma particular, do trabalho com a leitura e compreensão discursiva. A perspectiva dialógica, tomada como fundamento para a análise de enunciados presentes em atividades de um livro didático do ensino médio, situa esta pesquisa como mais uma reflexão propulsora das relações entre a Teoria Dialógica da Linguagem e as práticas de ensino de Língua Portuguesa.

As discussões apresentadas alertam para a necessária adoção de uma concepção dialógica de linguagem por parte de professores de Língua Portuguesa na educação básica, os quais, seguindo tal orientação, podem reformular diferentes atividades propostas pelos variados materiais didáticos que são disponibilizados nas escolas. Essa autonomia é significativa e relevante para que a prática docente deixe de ser taxada como reprodução de discursos e práticas tradicionais e possa de modo efetivo estimular um trabalho dinâmico e concreto com as facetas que compõem a linguagem humana.

Os conceitos de dialogismo e axiologia mostram algumas das orientações que a Teoria Dialógica da Linguagem pode encaminhar para contextos de ensino e de aprendizagem de Língua Portuguesa, podendo, sobretudo, estender as proposições aqui levantadas para o trabalho pedagógico com as línguas estrangeiras. Com isso, a relação entre teoria e prática é vislumbrada de modo a demonstrar que a prática pedagógica é ofuscada, complexa e desafiadora, por isso não pode ser limitada ao que ditam como correto.

O foco no papel ativo do aluno, fundamental para o desenvolvimento significativo das atividades de leitura em sala de aula, é algo destacado pela discussão empreendida neste estudo. Esperamos que tais discussões possam nortear posicionamentos metodológicos e pedagógicos de professores de língua portuguesa e ensejem ainda mais a disposição para propor atividades que promovam atitudes responsivas ativas (BAKHTIN, 2006e [1979]) de seus alunos, constituindo a sala de aula como um espaço propício para o exercício da construção de pontos de vista.

\section{Referências}

BAKHTIN, Mikhail. Para uma filosofia do ato responsável. Trad. Valdemir Miotello e Carlos Alberto Faraco. São Carlos: Pedro \& João Editores, 2010.

BAKHTIN, Mikhail. O discurso em Dostoiévski. In: BAKHTIN, Mikhail. Problemas da poética de Dostoiévski. Rio de Janeiro: Forense, 2005 [1963], p. 207-310.

BAKHTIN, Mikhail. O autor e o herói na atividade estética. In: BAKHTIN, Mikhail. Estética da criação verbal. Trad. Paulo Bezerra. 4. ed. São Paulo: Martins Fontes, 2006a [1979]. p.320.

BAKHTIN, Mikhail. O todo temporal da personagem. In: BAKHTIN, Mikhail. Estética da criação verbal. Trad. Paulo Bezerra. 4. ed. São Paulo: Martins Fontes, 2006b [1979]. p.91126.

BAKHTIN, Mikhail. O problema do autor. In: BAKHTIN, Mikhail. Estética da criação verbal. Trad. Paulo Bezerra. 4. ed. São Paulo: Martins Fontes, 2006c [1979]. p. 173-194.

BAKHTIN, Mikhail. Metodologia das ciências humanas. In: BAKHTIN, Mikhail. Estética da criação verbal. Trad. Paulo Bezerra. 4. ed. São Paulo: Martins Fontes, 2006d [1979]. p. 393410.

BAKHTIN, Mikhail. Reformulação do livro sobre Dostoiévski. In: BAKHTIN, Mikhail. Estética da criação verbal. Trad. Paulo Bezerra. 4. ed. São Paulo: Martins Fontes, 2006e [1979]. p. 393-410.

BAKHTIN, Mikhail. Os gêneros do discurso. In: BAKHTIN, Mikhail. Estética da criação verbal. Trad. Paulo Bezerra. 4. ed. São Paulo: Martins Fontes, 2006f [1979]. p. 393-410. 
BAKHTIN, Mikhail. Questões de estilística no ensino da língua. Tradução, posfácio e notas de Sheila Grillo e Ekaterina Vólkova Américo. São Paulo: 34, 2013a [1934].

BEZERRA, J. C. S. Perspectivas axiológicas nas propostas de atividades relacionadas à compreensão de texto na obra "Português: Linguagens 1". In: SILVA JÚNIOR, S. N (Org.) Ensino e aprendizagem de línguas e literaturas: caminhos para o debate. Pará de Minas, MG: Virtual Books, 2017, p. 25-44.

BRAIT. Bakhtin e a natureza constitutivamente dialógica da linguagem. In: BRAIT, Beth (Org.). Bakhtin: dialogismo e a construção do sentido. $2^{\mathrm{a}}$ edição. Campinas, São Paulo: Editora da Unicamp, 2005.

BRAIT, Beth. PISTORI, Maria Helena Cruz. A produtividade do conceito de gênero em Bakhtin e o Círculo. Alfa, São Paulo, 56 (2): 371-401, 2012.

CEREJA, William Roberto; VIANNA, Carolina Assis Dias; DAMIEN, Christiane. Português contemporâneo - diálogo, reflexão e uso. Componente curricular: Língua Portuguesa $-1^{\circ}$ ano do Ensino Médio. $1^{\mathrm{a}}$ edição. São Paulo: Saraiva, 2016.

CEREJA, William Roberto. Significação e Tema. In: BRAIT, B (Org.) Bakhtin: conceitoschave. São Paulo: Contexto, 2005.

FRANCELINO, Pedro Farias. A autoria no gênero discursivo aula: uma abordagem enunciativa. Tese (Doutorado em Linguística). Programa de Pós-graduação da Universidade Federal de Pernambuco. Recife, 2007.

GERALDI, João Wanderley. Dialogia: do discursivo à estrutura sintática. In: HAMMESRODRIGUES, Rosangela; ACOSTA PEREIRA, Rodrigo (Orgs). Estudos dialógicos - da linguagem e pesquisa em linguística aplicada. São Carlos: Pedro e João Editores, 2016. p. 179190.

GERALDI, João Wanderley. Portos de Passagem. 4. ed. São Paulo: Martins Fontes, 1997.

GRILLO, Sheila. Marxismo e Filoso fia da linguagem: uma resposta à ciência da linguagem do século XIX e início do XX. Ensaio introdutório. (p. 42). In: VOLOCHÍNOV, V. N. (círculo de Bakhtin). Marxismo e filosofia da linguagem - Problemas fundamentais do método sociológico na ciência da linguagem. Tradução de Sheila Grillo e Ekaterina Vólkova Américo - Ensaio introdutório de Sheila Grillo. 1. ed. São Paulo: Editora 34, 2017.

HAMMES-RODRIGUES, Rosangela; ACOSTA PEREIRA, Rodrigo. Apresentação. In: HAMMES-RODRIGUES, Rosangela; ACOSTA PEREIRA, Rodrigo (Orgs). Estudos dialógicos - da linguagem e pesquisa em linguística aplicada. São Carlos: Pedro e João Editores, 2016. p. 9-16.

MEDVIÉDEV, P. A ciência das ideologias e suas tarefas imediatas. In: MEDVIÉDEV, Pável. O método formal nos estudos literários: introdução a uma poética sociológica. Tradutoras: Sheila Camargo Grillo e Ekaterina Vólkova Américo. São Paulo: Contexto, 2016a [1928], p.4156.

MEDVIÉDEV, P. A linguagem poética como objeto da poética. In: MEDVIÉDEV, Pável. O método formal nos estudos literários: introdução a uma poética sociológica. Tradutoras: Sheila Camargo Grillo e Ekaterina Vólkova Américo. São Paulo: Contexto, 2016b [1928], p.131-163.

MENEGASSI, R. J; CAVALCANTI, R. S. M. Conceitos axiológicos bakhtinianos em propaganda impressa. Alfa: Revista de Linguística (UNESP. Online), v. 57, p. 433-449, 2013. ROCHA, R. B. S. S. Estilo, expressividade e axiologia no ensino-aprendizagem da língua em uso. Bakhtiniana - Revista de Estudos do Discurso, v. 13, p. 155-175, 2018.

SANTANA, Wilder Kleber Fernandes de. Dialogismo em foco: variações semânticoaxiológicas e sua aplicabilidade. In: SANTANA, Wilder Kleber Fernandes de. Relações linguísticas e axio(dia)lógicas: sobre linguagem e enunciação. João Pessoa: Ideia, 2019. p. 8493; 
Volume 15 - Número 1 - jan/jul de 2020

SANTANA, Wilder Kleber Fernandes de. SILVEIRA, Éderson Luís. Reflexos e refrações educacionais: do dizer ao fazer (Apresentação). In: SANTANA, Wilder Kleber Fernandes de. SILVEIRA, Éderson Luís (Orgs.) Educação: ressonâncias teóricas e práticas. Volume 1. São Carlos: Pedro \& João Editores, 2019.

SILVA JÚNIOR, Sílvio Nunes. Produção oral sistematizada em atividades didáticas de língua portuguesa: um trabalho colaborativo no ensino fundamental. Dissertação (Mestrado em Linguística), Programa de Pós-graduação em Linguística e Literatura, Universidade Federal de Alagoas, 2019.

VOLÓCHINOV, Valentin. Duas tendências do pensamento filosófico-linguístico. In: VOLOCHÍNOV, V. N. (círculo de Bakhtin). Marxismo e filosofia da linguagem - Problemas fundamentais do método sociológico na ciência da linguagem. Tradução de Sheila Grillo e Ekaterina Vólkova Américo - Ensaio introdutório de Sheila Grillo. 1. ed. São Paulo: Editora 34, 2017a [1929]. p. 143-172.

VOLÓCHINOV, Valentin. A Interação Discursiva. In: VOLOCHÍNOV, V. N. (círculo de Bakhtin). Marxismo e filosofia da linguagem - Problemas fundamentais do método sociológico na ciência da linguagem. Tradução de Sheila Grillo e Ekaterina Vólkova Américo - Ensaio introdutório de Sheila Grillo. 1. ed. São Paulo: Editora 34, 2017b [1929]. p. 201-226. VOLOCHINOV, Valentin. A palavra na vida e a palavra na poesia: para uma poética sociológica. In: VOLOCHINOV, Valentin (Círculo de Bakhtin). A palavra na vida e a palavra na poesia - Ensaios, artigos, resenhas e poemas. Tradução de Sheila Grillo e Ekáterina Vólkova Américo. São Paulo: Editora 34, 2019 [1926].

ZOZZOLI, R. M. D. Conhecimentos linguístico-discursivos na sala de aula de língua portuguesa: desenvolvendo "táticas" para desobedecer a propostas prontas. Leia Escola, Campina Grande, v. 14, n. 1, p. 40-50, 2014.

Submetido em 30/04/20

Aceito em 31/07/20 